\title{
Risk and the decision to produce biomass crops: a stochastic analysis
}

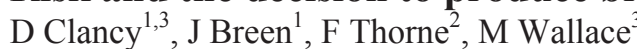

${ }^{1}$ Rural Economy Research Centre, Teagasc, Athenry, Co. Galway, Ireland

${ }^{2}$ Rural Economy Research Centre, Teagasc, Kinsealy, Dublin 17, Ireland

${ }^{3}$ School of Agriculture, Food Science and Veterinary Medicine, University College Dublin, Belfield, Dublin 4, Ireland

Email: daragh.clancy@teagasc.ie

Introduction There is increasing interest in biomass crops as an alternative farm enterprise however given the relatively low uptake of these crops in Ireland, there is limited information concerning the risk associated with their production and its impact on returns. The uncertainty surrounding risky variables such as the costs of production, yield level, price per tonne and opportunity cost make it difficult to accurately calculate the returns to biomass crops. The lengthy production lifespan of these crops may only serve to heighten the level of risk that affects key variables. This analysis aims to measure the degree of risk in the returns from biomass crops, and compare that to the risk faced by conventional agricultural enterprises.

Materials and methods In this analysis a stochastic budgeting model, is used to calculate the returns from willow and miscanthus. Stochastic budgeting is an improvement on the traditional deterministic approach as it involves attaching probabilities of occurrence to the possible values of the key variables in a budget, thereby generating the probability distribution of possible budget outcomes. The selected variables to be added stochastically should comprise those that will have the largest effect on the level of risk of the outcome. The stochastic variables included in the model are costs, yields and prices, which Clancy et al. (2009) have shown a large effect on the returns from biomass crops. The hierarchy of variables approach was used to calculate the stochastic costs and prices of willow and miscanthus, while the stochastic yields are derived from an empirical distribution of the historical data. The Cumulative Distribution Function (CDF) of the stochastic gross margins (GM) from the biomass crops is used to elicit ten discrete states of potential returns, with each having an equal probability of occurrence. The opportunity cost of land is accounted for through the inclusion of foregone returns from a conventional agricultural activity, such as spring barley, winter wheat or store to finished beef. The estimation of parameters of the probability distribution of these stochastic enterprises GM was empirically based, with National Farm Survey (NFS) data from 1997 - 2006 used to calculate their financial performance. The biomass discrete states and the historical conventional gross margins are used as parameters in a Multivariate Empirical (MVE) distribution to simulate the financial performance of all enterprises over a 16 year planning horizon. The results of this simulation are then compared using their respective CDF and the enterprises are ranked using Stochastic Efficiency with Respect to a Function (SERF).

Results SERF uses risk premiums to determine the confidence of decision makers in a particular preferred risky alternative. The risk premium reflects the minimum sure amount that would have to be paid to a decision maker to justify a switch from the dominant alternative to a less preferred option. Figure 1 shows that while farmers would need a substantial risk premium to be persuaded to switch from any conventional enterprise to willow, miscanthus is relatively competitive with all but Winter Wheat. This suggests that a greater level of risk is associated with willow than conventional enterprises, and that miscanthus may be a viable alternative to some of these systems.

Figure 1 Risk Premiums for each enterprise relative to willow

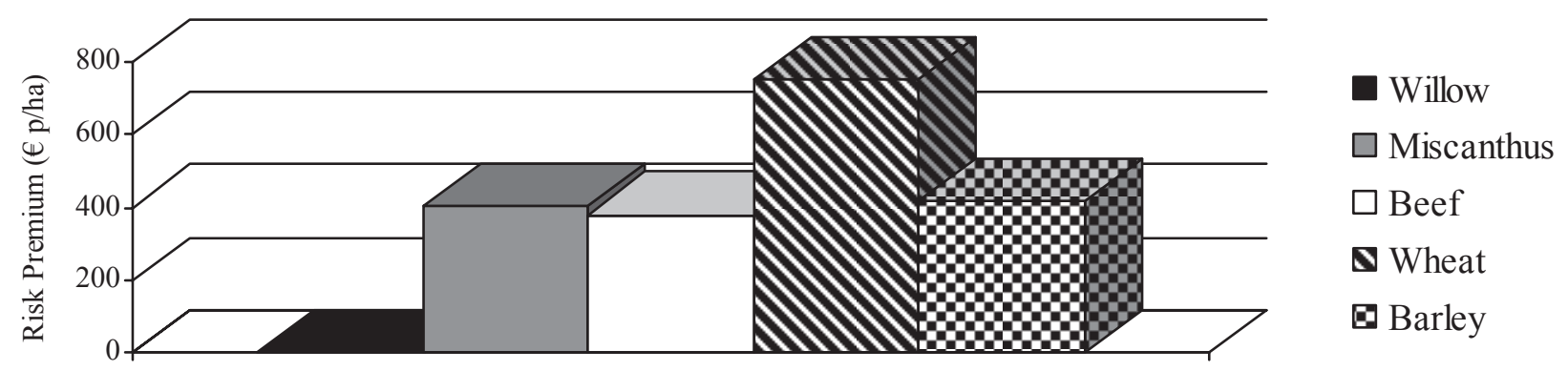

Conclusions Uncertainty regarding the returns from biomass has manifested itself in a reluctance of farmers to enter production, and this may be a key factor in the low planting rates to date. This analysis found that accounting for risk underlined the results of the baseline economics from Clancy et al. (2009), who found that under given assumptions and costings, miscanthus has a greater level of return than willow. The results from this analysis tell a similar tale with miscanthus having a lower risk premium than willow. The value of the risk premium required to entice farmers to switch to miscanthus production is significantly less than that required for willow, suggesting a greater level of risk is associated with willow than with miscanthus.

Acknowledgements The authors gratefully acknowledge funding from the Research Stimulus Fund, DAFF

\section{References}

Clancy, D., Breen, J., Butler, A.M., Thorne, F., Wallace, M. 2009. Journal of Farm Management 13, 1- 17. 